\title{
Study on Strategy in University Laboratory Class Teaching
}

\author{
Haoxi Zhang ${ }^{1, *}$ and Edward Szczerbicki ${ }^{2}$ \\ ${ }^{1}$ Chengdu University of Information Technology, Chengdu, China \\ ${ }^{2}$ Gdansk University of Technology, Gdansk, Poland \\ ${ }^{*}$ Corresponding author. Email: haoxi@cuit.edu.cn
}

\begin{abstract}
Laboratory teaching is a critical way to ensure the effective input of techniques in engineering learning. Laboratory teaching not only contributes to improving course quality but also helps enrich comprehensive engineering application ability. However, there are some typical problems in current university laboratory teaching, such as rigid and isolated course design, outdated contents and materials, and not encouraging innovation and real-world problem solving. To overcome these challenges, a three-step teaching reconstruction strategy has been proposed to enhance university educators' teaching effects, including introduce new laboratory teaching methods, updating contents and materials, and organizing innovative and multi-discipline Learning. Through efforts made by university teachers, students, and industry partners, the goal can be achieved by following the proposed strategy.
\end{abstract}

Keywords: Laboratory teaching, Engineering education, Science experiments teaching, Teaching approaches, University Classes.

\section{INTRODUCTION}

For around twenty decades, science and engineering educators have stated that laboratory teaching and practice enhance students' understanding of the natural world [1][2]. Over the years, many have argued that only engineering courses with worthwhile practical experiments can be meaningful to students in the university laboratory [3].

Laboratory teaching is a critical way to ensure the effective input of techniques in engineering learning. Laboratory teaching not only contributes to improving course quality but also helps enrich comprehensive engineering application ability. Moreover, these skills and techniques learned in the laboratory are the key qualifications for students getting a job in the industry once they graduate from their university studies.

Based on the study and analysis of some typical problems in current university laboratory teaching, this paper proposes a practical strategy to improve laboratory teaching and learning for contemporary university students in order to help them master realworld problem solving and better adapt to the current fast-developing technology and industrial environment in China.

\section{TYPICAL PROBLEMS IN CURRENT UNIVERSITY LABORATORY TEACHING}

\subsection{Rigid and Isolated Course Design}

Laboratory teaching is one of the most popular approaches for getting students actively involved in the learning process of a subject, especially for science and engineering disciplines. It is also an effective educational method for universities to train applied engineering students. However, in many courses, the teaching content is still mainly aimed at theoretical knowledge teaching but practical skills training, and the teaching content is usually organized based on basic knowledge of one particular subject. As a result, the laboratory experiments are rigidly designed according to the course content as well as the basic theoretical knowledge teaching aim. Focusing on theoretical knowledge teaching can lead to a lack of necessary implementation skills that are crucial for one's future career success. Also, students can hardly improve their practical skills through laboratory classes.

Moreover, focusing on basic textbook knowledge ignores industrial problems, which makes university courses not only isolated from the real world but also 
isolated from each other, because, in today's industry, a problem often involves knowledge of several disciplines and topics [4]. For example, in the course Software Engineering, the students are asked to master the software life-cycle, and learn a range of diagrams, like use-case diagram, data-flow diagram, etc. However, without real industry projects and experienced engineers, the instructor can hardly make the class juicy. Students usually feel bored during the learning, and perform poorly in the laboratory classes when they make the Software Requirements Specifications. In order to make this course interesting, the teacher should design the lectures based on real-world projects, which involves knowledge from different disciplines. Otherwise, the course will become rigid and dry.

Rigid and isolated course design makes it very hard for students to solve real-world problems by using learned knowledge. This is very harmful to engineering education and the country's industry.

\subsection{Outdated Contents and Materials}

Continuous change and rapid progressing are the main challenges for today's engineering companies. Accordingly, engineering courses shall be updated as soon as possible [5]. Unfortunately, university educators are not tightly connected with industry. Therefore, laboratory teaching contents and materials are mostly outdated. For instance, the course Data Science, it requires students to know how to acquire useful information from raw data by using a number of techniques. However, sometimes, university uses outdated or impractical tools for teaching, like using Matlab or Weka, they are good for demonstrating the basic ideas, but they are barely used by high-tech companies. If students don't learned popular tools in their field, it will be difficult to them to develop demanded skills and find good jobs. Moreover, the neural networks and deep learning are hot topics these days, but they are not included in many textbooks yet. This also makes students outdated.

Additionally, it is hard to force professors to catch up with the latest industrial concepts and frontier engineering techniques because professors are usually focusing on very specific research problem, and they don't need to work for the industry as an engineer. Thus, it is hard to them to pay more attend to what is going on in industry. If the professors are not familiar with popular techniques and tools, then the courses will be outdated. As a result, students are often passive in laboratory experiments, and it makes the problem even worse.

\subsection{Not Encouraging Innovation and Real- world Problem Solving}

Existing laboratory teachings are usually specifictopic-oriented. In other words, one experiment or one laboratory class is commonly designed to one particular course. For example, in the course of Data Science, there is a chapter on Data Visualization, which introduces a range of different plots and tools for visualizing the data. Consequently, in its laboratory class, students are asked to master the process of how to generate these plots. This means, the laboratory class is designed to guide student draw diagrams based on fixed datasets rather than developing students' analytical ability and thinking skills.

It is obvious that if the university laboratory teaching keep current states, it will be very hard to meet the expectation for it, which is training future engineers who are able to analyze newly obtained data, study realworld problems, and address constantly changing conditions.

\section{STRATEGIE ON THE RECONSTRUCTION OF UNIVERSITY LABORATORY TEACHING}

Today, both the industry and technology are progressing rapidly. Together with the nature of engineering courses (i.e. abstract and complex), not to mention the mathematics, engineering education is becoming increasingly harder to effectively achieve its goal. As a result, it is difficult for educators and students to gain good outcomes.

To overcome these challenges and problems, in this section, we propose a three-step reconstruction strategy for university laboratory teaching to enhance university educators' teaching effects. This proposed strategy is focusing on addressing these three previously mentioned problems and to allow students to effectively learn and master the skills and techniques required of the course. Also, by following the 3-step reconstruction of the laboratory teaching, it is possible for students to have a higher level of understanding about the course as well as the discipline during the learning.

\subsection{Introducing New Laboratory Teaching Methods}

The traditional laboratory teaching is more like a one-way-input approach. During the teaching, the teacher demonstrates in front of the class, and students are expected to learn by watching what the teacher is doing or reading of an instruction guide. Such form of teaching approach usually focuses on single theoretical ideas. In other words, the instructor is meant to explain only one idea once a time, so that the students can hardly put learned ideas together and have higher-level 
understanding about the subject. Also, it is hard to students to gain practical skills while taking traditional laboratory classes like this.

Therefore, there is a need to redesign traditional laboratory classes to allow students to learn by various means. Project-based [6] or problem-based learning [7] is one of the main successful approaches broadly used in computing science courses. However, it can be insufficient when tackling practical problems that implicitly require many functions and timely feedback. For instance, in course Software Engineering, if the teacher use the project-based approach, it will be much better for students to follow the class in comparison with traditional teaching method because the projectbased approach can give students a clear goal at the very beginning. To have a clear goal at the beginning will allow students to understand the big picture and each step of the laboratory teaching. But, if the project is based on a real-world problem, then a domain expert is demanded, otherwise, the students can hardly investigate the problem deeply and insightfully. Moreover, in software engineering, if there is lack of domain experts, the software engineers will most likely have problems with confirmation of requirements because the engineers know neither what the real requirements are nor how the task's procedures are. Hence, even teachers can take project-based or problembased method, but it still can be insufficient or unsuccessful if there are not experienced engineers and domain experts involved in the teaching team. Therefore, in order to succeed in new laboratory teaching methods, experienced experts are needed to co-design the materials and experiments in order to ensure the students can learn practical skills during the course.

\subsection{Updating Contents and Materials}

The university laboratory teaching contents and materials are usually outdated, which makes it not only hard to attract students' interest but also hard to have good teaching outcomes. Furthermore, outdated contents and materials can cause the students to be outdated too, which will have a big impact on them when they start to look for jobs. Also, if most of the universities are teaching outdated contents, the industry will be affected too.

Thus, it is urgent to find a way that can motivate university teachers to improve and update their course contents and materials every year. Industry-oriented cooperation is good way, and it can be beneficial for both universities and companies. By having cooperative connections with companies, the university can have a better understanding of the real demand from industry. University teachers can visit the companies and have meeting with real-world problem solvers in the company and learn from them. At the meantime, companies can send their engineers to universities to co- design the courses and prepare the materials according to their real-world problems, so that the industry can have better students who are able to solve their problems in return.

\subsection{Organizing Innovative and Multi- Discipline Learning}

Real-world problem solving often involves knowledge of multiple disciplines and requires the ability to analyze novel data under different conditions.

In order to enhance students with thinking skills and help them connect multi-disciplinary knowledge together to solve real-world problems, the traditional laboratory teaching needs to be changed from being single-topic focused towards multi-discipline integrated. Also, the laboratory classes shall be organized as problem-oriented rather than traditional content-oriented where students learn from reading-lists [8][9]. If the university can build well cooperative connections with companies, then the teachers will learn real-world problems, and the multi-discipline integrated course will be possible.

Moreover, to meet the expectations for future engineers, the teaching shall be dedicated to strengthen not only the students' skills in analysis and evaluation of complex problems but also the skills of teamwork that solving multi-disciplinary problems [10].

\section{CONCLUSION}

This paper proposes a strategy by solving existing problems in a targeted way. On the one hand, university educators should improve their course contents, introduce new laboratory teaching methods, and design up-to-date materials. On the other hand, establish cooperative connections with industry are beneficial for both students and companies, which allows effective communication between educators and employers. Furthermore, laboratory teaching should also change toward improving students' real-world problem-solving skills.

In conclusion, it will be a long-term work to improve current universities' engineering laboratory teaching. However, it is necessary and worth changing. Most importantly, only through efforts made by university teachers, students, and industry partners, the goal can be achieved by following the proposed strategy.

\section{ACKNOWLEDGMENTS}

This work was supported by the Sichuan Science and Technology Program under Grant 2019YFH0185. 


\section{REFERENCES}

[1] Edgeworth, R. L., \& Edgeworth, M.: 1811, Essays on practical education. London: Johnson.

[2] Rosen, S. A. (1954). History of the physics laboratory in American public schools (to 1910). American Journal of Physics, 22, 194-204.

[3] Bretz, Stacey Lowery. Evidence for the importance of laboratory courses. (2019): 193-195.

[4] Woods D. R., Felder R. M., Rugarcia A., Stice J. E. The future of engineering education III. Change, 2000; 4: 48-52.

[5] Mills J. E., Treagust D. F. Engineering educationIs problem-based or project-based learning the answer. Australasian journal of engineering education, 2003; 3: 2-16.

[6] Macias, José A. "Enhancing project-based learning in software engineering lab teaching through an eportfolio approach." IEEE Transactions on Education 55, no. 4 (2012): 502-507.
[7] Perrenet, Jacob C., Peter AJ Bouhuijs, and Jan GMM Smits. "The suitability of problem-based learning for engineering education: theory and practice." Teaching in higher education 5, no. 3 (2000): 345-358.

[8] ElMaraghy W. H. Future trends in engineering education and research. In Advances in Sustainable Manufacturing. Springer; 2011; 11-16.

[9] Froyd J. E., Wankat P. C., Smith K. A. Five major shifts in 100 years of engineering education. Proceedings of the IEEE, 2012; 100: 1344-1360.

[10] Felder R. M., Woods D. R., Stice J. E., Rugarcia A. The future of engineering education II. Teaching methods that work. Chemical Engineering Education, 2000; 34: 26-39. 